\title{
Colorectal cancer-number of lymphnodes (LN) examinate
}

\author{
Kiss Lorant*, Bartos Laura, Alexa Doina, Kiss Rolanda and Zaharia Sorin \\ Department of Patology, 1st Surgical Clinic, Emergency Academic Hospital Sibiu, University Lucian Blaga of Sibiu, Romania
}

\begin{abstract}
We analyzed retrospectively surgical specimens from 345 colorectal cancer. The aim was to estimate the value of sampling lymph nodes (LN) located far sidelong colorectal cancer specimens. The fat from the mesocolon and perirectal space was divided into 2 fractions: close to (less than $5 \mathrm{~cm})$ and distant $(\mathrm{more}$ than $5 \mathrm{~cm})$ from the tumor.

Tumors was located in the cecum ( $\mathrm{n}=61)$, ascending colon $(\mathrm{n}=29)$, transverse colon $(\mathrm{n}=31)$, descending colon( $\mathrm{n}=27)$, sigmoid colon( $\mathrm{n}=108)$, rectum( $\mathrm{n}=89)$. The median number of LN sampled was 17 in the both fractions (range 4-26),12(range=0-21), in the close fraction and 3(range0-28),in the distant fraction.

There were $169 \mathrm{pNo}, 104 \mathrm{pN} 1$, and $72 \mathrm{pN} 2$ cases. The $\mathrm{pN}$ staging was accurate, except 10 based on the close fraction alone: of these, 6 were upstaged from pNo to pN1 and 4 from pN1 to pN2, were the distant fraction was considered. In the colon, we found that LN location is more important than LN number because metastasic LN were present mostly in the peritumoral area. The suggests that LN should be initially recovered from the pericolic fat, close to the tumor.

If there are less than 4 positive LN and less than $12 \mathrm{LN}$ examined in total, additional LN should be retrieved from the distal fraction for potential upstaging.

In the rectum, systematic sampling of close and distant LN is very important because rare cases, metastases are detected only in the distant LN, particularly at the patients who have undergone neoadjuvant radiotherapy.
\end{abstract}

\section{Introduction}

The presence of LN metastases in colorectal cancer is currently the most important factor in determining the indication for adjuvant therapy and is on the most important factor in estimation survival [16]. The total number of LN examined from colorectal cancer surgical specimens is associated with improved survival possibly because of increased accuracy in staging $[2,6,7]$. Cohen showed that the number of positive $\mathrm{LN}$ was related inversely to prognosis ( $\mathrm{pN} 1,66 \% 5$ years survival), with the optimal dichotomization between 1 to 3 , and 4 or more LN (pN2,37\% 5 years) $[1,8]$.

Recovering a larger number of $\mathrm{LN}$ reduces the possibility of missing a metastatic LN. The total number of LN required for adequate staging has long been a matter of controversy. The results from different series suggest that a minimum of 6 to $17 \mathrm{LN}$ should be investigated for reliable node-negative staging [2-5,9] and the American Joint Committee on Cancer (AJCC) and IUAC (International Union Against Cancer) recommend a minimal assessment of $12 \mathrm{LN}$ for accurate staging $[10,11]$. The extent of intestinal resection for colorectal cancer is related to the vascularization of the colon and rectum. This leading surgeon to resect broader regions than considered strictly necessary from an oncologic point of view.

The contribution made by LN located in adjacent tissues relatively distant from the colorectal cancer was not investigated and their relative roles have not been taken into account in nodal staging. Systematic sampling of LN located in adjacent fat tissue relatively far from the colorectal cancer is both expensive and time-consuming and few studies have addressed it is a potential impact on $\mathrm{pN}$ status [9].

To determinate the value of systematically sampling distant LN in colorectal cancer surgical specimens in which the mesocolic and perirectal fat was divided into 2 fractions one close to the tumor (less than $5 \mathrm{~cm}$ ) and the other distant from the tumor (more than $5 \mathrm{~cm}$ from both sides of the tumor).

\section{Materials and methods}

In this retrospectively study, we reviewed reports from the Pathology Department of Sibiu, from the 1st Surgical Clinic for all primary colorectal cancer surgical specimens collected between 20032014. A total 498 cases were reviewed, and 153 cases were excluded from the study because 10 cases of secondary excision for local tumor recurrence, 24 cases of multiple tumors and 119 cases in which proximal and distal fraction of the mesocolic and perirectal fat was not adequately individualized from colorectal cancer during microscopy.

In total 345 cases were eligible for this study. Among the patients who have rectal cancer $(n=89), 28 \%(n=25)$ had been treated with neoadjuvant radiotherapy, the rest of the patients benefited from postoperative radiotherapy as it was recommended in our hospital during the period. The mesocolic fat was divided to harvest $\mathrm{LN}$ from the colon cancer surgical specimens into fractions A and B. Fraction A was close to the tumor (less than $5 \mathrm{~cm}$ from both sides of the tumor). Fraction B was distant from the tumor (more than $5 \mathrm{~cm}$ ). In colorectal tumor the direct extension of tumor cells in the intestinal wall did not occur more than $5 \mathrm{~cm}$ far from the primary tumor [12-14].

To guarantee Ro resection independently from LN and/or anatomic or vascular consideration a $5 \mathrm{~cm}$ safety surgical border was

${ }^{\star}$ Correspondence to: Kiss Lorant, Department of Patology, 1st Surgical Clinic, Emergency Academic Hospital Sibiu, University Lucian Blaga of Sibiu, Romania, E-mail: drkisslorant@yahoo.com

Received: December 14, 2018; Accepted: January 03, 2019; Published: January 10,2019 
considered to be adequate. To harvest the LN of rectal cancer the perirectal fat (fraction A) and the perisigmoidian fat (fraction B) were separated. The same approach was exactly used for $\mathrm{LN}$ dissection in fraction $\mathrm{A}$ and $\mathrm{B}$. The 2 fractions were separated into 2 different bottles and LN sampling was made the next day. LN staging was defined according to the TNM classification as $\mathrm{pNo}(0$ positive $\mathrm{LN}), \mathrm{pN} 1(1-$ 3 positive $\mathrm{LN}$ ), a d pN2 (4 or more positive) [10,11]. Cutoff values of 12 or $18 \mathrm{LN}$ were chosen according to the minimum number of LN recommended by the IUACC and according to Goldstein $[4,5]$ who recommend a higher number (more than 18) of LN.

\section{Results}

The number of $\mathrm{LN}$ in colorectal cancer surgical specimens is stored in Table 1. Tumors was located as follows: cecum $(n=61)$, ascending colon $(n=29)$, transverse colon $(n=31)$, descending colon $(n=22)$, sigmoid and rectosigmoidian junction $(n=108)$ and $\operatorname{rectum}(n=89)$. The mean number of $\mathrm{LN}$ recoverd from location was as follows: cecum $(\mathrm{n}=18)$, ascending colon $(\mathrm{n}=20)$, transvers colon $(\mathrm{n}=19)$ descending colon $(n=17)$, sigmoid and rectosigmoidian junction $(n=17)$ and rectum $(n=10)$. The mean number of total LN sampled was significantly higher in the ascending and transverse colon and significantly lower in the rectum $(\mathrm{p}=0.0001)$.

The mean number of LN sampled in both fractions was 18 , the mean number of LN from the close and distant fractions respectively were 13 and 4,9 which is statistically significant. The relationship between tumor infiltration (pT stage) and the LN status (pN stage) is shown in Table 2.

There were 11 pT1 42 pT2 20 pT3 and 87 pT4,169 pNo, 10 $\mathrm{pN} 1,72 \mathrm{pN} 2$. There was no significant difference in the LN mean number among pNo, pN1 and pN2 whereas the LN mean number was significantly bigger in pT3 and pT4 tumors (both 19) compared with pT1and pT2 tumor (14 and 15 respectively, $\mathrm{p}=0,0031$ ).

The percentages of LN found in fractions A and B were respectively $58 \%$ and $42 \%$ for pT $1,70 \%$ and $30 \%$ for pT2,74\%and $26 \%$ forpT3 and $73 \%$ and $27 \%$ for pT4 tumors. The relationship between total LN count and the number of patients with positive LN is shown in Table 3.

The number of patients with positive LN was significantly bigger (59\%) when they had at least $12 \mathrm{LN}$ sampled compared with patients from whom less than $12 \mathrm{LN}$ were sampled $(45 \% \mathrm{p}=0,127)$. There was no significant difference between the group of patients with less than 12 LN sampled (46\%) and the group with more than $12 \mathrm{LN}$ but less than $18 \mathrm{LN}$ sampled (44\%) $\mathrm{p}=88,60$.

When only LN from fraction A (close to the tumor) were considered the $\mathrm{pN}$ ( $\mathrm{pN} 0, \mathrm{pN} 1, \mathrm{pN} 2)$ would have been accurate in $97 \%$ of colorectal

Table 1. LN status and location of tumors

\begin{tabular}{|c|c|c|c|c|}
\hline Tumor location & $\begin{array}{c}\text { Number of } \\
\text { cases }\end{array}$ & $\begin{array}{c}\text { Mean total } \\
\text { number of LN }\end{array}$ & $\begin{array}{c}\text { Mean number } \\
\text { of LN in the } \\
\text { close fracture }\end{array}$ & $\begin{array}{c}\text { Mean number } \\
\text { of LN in the } \\
\text { distal fracture }\end{array}$ \\
\hline Cecum & 61 & 18 & 13 & 4,6 \\
\hline Ascendent colon & 29 & 20 & 14 & 5 \\
\hline Transverse colon & 31 & 19 & 12 & 8 \\
\hline $\begin{array}{c}\text { Descendent } \\
\text { colon }\end{array}$ & 27 & 17 & 11 & 4 \\
\hline $\begin{array}{c}\text { Sigma, } \\
\text { rectosigmoid } \\
\text { junction }\end{array}$ & 108 & 17 & 14 & 3,8 \\
\hline Rectum & 89 & 10 & 12 & 3,9 \\
\hline
\end{tabular}

Total 345
Table 2. Relationship between $\mathrm{pT}$ stage, $\mathrm{pN}$ stage and LN number

\begin{tabular}{|c|c|c|c|c|c|}
\hline & pN0(№) & pN1(№) & pN2(№) & Total & № mean LN \\
\hline pT1 n\% & $10(91)$ & $0(0)$ & $1(9)$ & 11 & 14 \\
\hline pT2 n\% & $26(62)$ & $13(31)$ & $3(7)$ & 42 & 15 \\
\hline pT3 n\% & $102(50)$ & $62(30)$ & $41(20)$ & 205 & 19 \\
\hline pT4 n\% & $31(36)$ & $29(44)$ & $27(31)$ & 87 & 19 \\
\hline Total & 169 & 18.2 & 19.5 & & \\
\hline LN mean № & 18 & 18,2 & 19,5 & & \\
\hline
\end{tabular}

Table 3. Relationship between total LN count and LN metastasis

\begin{tabular}{|c|c|c|c|c|c|c|c|c|}
\hline \multirow{2}{*}{$\begin{array}{c}\text { Total } \\
\text { LN } \\
\text { count }\end{array}$} & \multirow{2}{*}{$\begin{array}{c}\text { Number } \\
\text { of } \\
\text { patients }\end{array}$} & \multicolumn{3}{|c|}{$\begin{array}{l}\text { Number of patients } \\
\text { with + nodes }\end{array}$} & \multicolumn{3}{|c|}{$\begin{array}{c}\text { Number of patients with } \\
+ \text { nodes }\end{array}$} & \multirow{2}{*}{$\begin{array}{l}\text { Number of } \\
\text { upstaged } \\
\text { cases in } \\
\text { fraction B }\end{array}$} \\
\hline & & Total & $\mathrm{pN} 1$ & $\mathrm{pN} 2$ & $\begin{array}{l}\text { In } \\
\mathrm{A}\end{array}$ & $\begin{array}{l}\text { In } \\
\mathrm{B}\end{array}$ & In $A+B$ & \\
\hline$<12$ & 93 & $\begin{array}{c}43 \\
(46 \%)\end{array}$ & $\begin{array}{c}24 \\
(56 \%)\end{array}$ & $\begin{array}{c}19 \\
(44 \%)\end{array}$ & $3580 \%$ & $\begin{array}{c}2 \\
5 \%\end{array}$ & $\begin{array}{c}6 \\
15 \%\end{array}$ & $\begin{array}{l}2 \text { to } \mathrm{pN} 1 \text { and } \\
3 \text { to } \mathrm{pN} 2\end{array}$ \\
\hline $\begin{array}{l}\geq 16 \\
<20\end{array}$ & 104 & $\begin{array}{c}46 \\
44 \%\end{array}$ & $\begin{array}{c}33 \\
72 \%\end{array}$ & $\begin{array}{c}13 \\
28 \%\end{array}$ & $\begin{array}{c}42 \\
92 \%\end{array}$ & $\begin{array}{c}2 \\
4 \%\end{array}$ & $\begin{array}{c}2 \\
4 \%\end{array}$ & $\begin{array}{l}2 \text { to } \mathrm{pN} 1 \\
1 \text { to } \mathrm{pN} 2\end{array}$ \\
\hline $12-16$ & 148 & $\begin{array}{c}87 \\
59 \%\end{array}$ & $\begin{array}{c}47 \\
54 \%\end{array}$ & $\begin{array}{c}40 \\
46 \%\end{array}$ & $\begin{array}{c}72 \\
84 \%\end{array}$ & $\begin{array}{c}2 \\
1 \%\end{array}$ & $\begin{array}{c}13 \\
15 \%\end{array}$ & 2 to $\mathrm{pN} 1$ \\
\hline Total & 345 & 176 & 104 & 72 & 149 & 6 & 21 & 0 \\
\hline
\end{tabular}

cancer specimens. After examining LN from fractions, A and B,6 of these 10 cases were upstaged from $\mathrm{pN} 0$ to $\mathrm{pN} 1$ and 4 were upstaged from $\mathrm{pN} 1$ to $\mathrm{pN} 2$. In $93(27 \%)$ cases, less than $12 \mathrm{LN}$ were sampled in the proximal and distal fractions of mesorectal and pericolic fat and in $160(46 \%)$ cases, less than $12 \mathrm{LN}$ were sampled in the proximal alone.

\section{Discussion}

In surgical resection in patients with colorectal cancer, it is very important to remove on bloc the tumor with adequate proximal and distal bowel regions to include any submucosae lymphatic areas to which metastases might spread, including the regional mesenteric draining lymphatic system.

Despite these guidelines, there is an evident amount of variability in the type of resection performed for colorectal cancer. which could lead to variability in the number of $\mathrm{LN}$ removed.

The number of LN found in surgical specimens varies from patients, depending on several factors, including tumor localization, the pathologic examination and the method used to harvest LN $[2,3,6,15-$ $18]$.

Canessa showed that the mean number of LN found in colorectal cancer surgical specimens varies from 62 to 36 with manual dissection alone. Hence, the minimum recommended number of $12 \mathrm{LN}$ cannot be guaranteed for every colorectal cancer specimen [19]. In many cases the average number LN examined per patient is often lower than 12, suggesting that a large number of patients with colorectal cancer are staged inadequately $[3,17,20,21]$.

In some studies, up to $78 \%$ of patients have been less than the minimum required the number of LN staged [3]. These situations indicated the use of special techniques (acetal clearing) to try to reach the minimum required LN [19].

An optimal number of LN to be examined in colorectal cancer specimens probably does not exist [22] and some authors, therefore, recommended recovering as many $\mathrm{LN}$ as possible [22].

In our opinion, the problem is not so much the number of LN to be harvest as how to be detected those LN most susceptible to be metastatic. In this study, the mean number of total LN sampled was significantly 
higher in the ascending and transverse colon and significantly lower in the rectum $(\mathrm{p}=0,0001)$, with previous studies $[3,15]$ According to other studies $[16,23]$. we found that the mean number of $\mathrm{LN}$ retrieved was significantly higher in pT3, pT4 tumors compared with pT1 and pT2 tumors [14] $(p=0,037)$ suggesting that there is the close relationship between the tumor stage and detectable LN $[17,5]$.

Thorn found a positive correlation between tumor diameter and LN count, a possible explanation for these is that larger tumor is more likely to ulcerate [16]. The tumor necrosis, with an ulcerative process, would induce reactive changes in proximal $\mathrm{LN}$, with secondary enlargement of them, this facility the identification during the LN dissection. We also found that the median number of LN in the distant fraction was substantially lower than the median number of LN recovered from the close fraction and this result is consistent with other studies [9]. We found that the proximal /distal LN ratio increases with tumor $\mathrm{pT}$ stage. This is in accordance with the postulate that the total number of LN recovered depends primarily on their distance from the tumor and that if no other causes of lymph adenomegaly (Chron disease, diverticulitis). The LN identifiable by palpation are most often located very close to the tumor and only a small number of such nodes are found at distances of $3 \mathrm{~cm}$ or more from the edges. In our series the mean number of LN recovered from the distance fraction was 4,9 (range 0-19).

We found a positive correlation between the total LN count and the number of patients with positive LN patients with 18 or more LN routinely had more potentially metastatic LN than patients with less than $18 \mathrm{LN}(\mathrm{p}=0,127)$.

IN contrast there were no difference in LN metastases in cases with less than $18 \mathrm{LN}$ sampled compared with who had less than $12 \mathrm{LN}$ sampled. This result suggests that for minimum count $12 \mathrm{LN}$ it is not enough and that more LN should be sampled.

In this study we separate LN located in the proximal and distal fractions of the tumor, based on previous findings that direct extension of the tumor cells in the intestinal wall did not detect more than $5 \mathrm{~cm}$ apart from the primary tumor [12-14].

In our study we found that $85 \%$ of the metastatic LN were located proximal of the tumor and the ratio of distribution (proximal or distal of the tumor) of metastatic LN did not change significantly among patients with more or less than 12 or $18 \mathrm{LN}$ sampled.

In a study of 2427 patients with pT3 colorectal cancer resulted at a single institution over 45 years Goldstein et al. [4,5] showed that no minimum LN accurately or reliably stages all patients [17] and the predictive probability of identifying a single positive $\mathrm{LN}$ increased in a linear manner as the number of dissected LN increased.

In our study in the close fraction alone $46 \%$ of cases had less than 12 LN sampled and when both proximal and distal fractions were examined that number was decreased to $27 \%$. This finding suggests that be limiting the sampling area to less than $5 \mathrm{~cm}$ close to the tumor. We have more cases with a less than optimal number of dissected LN is expected.

The pathologic $\mathrm{pN}$ staging ( $\mathrm{pNo}, \mathrm{pN} 1$ and $\mathrm{pN} 2$ ) was accurate in all but $10(2,9 \%)$ of the 345 colorectal cancers when the proximal fraction alone was examined. Of the 10 cases, 6 were upstaged from pNo to $\mathrm{pN} 1$ and 4 from $\mathrm{pN} 1$ to $\mathrm{pN} 2$ when $\mathrm{LN}$ from the distant fraction were included.

The results confirm the results of a similar study from Cserni in which 100 colorectal cancers surgical specimens were analyzed prospectively and LN sampled were separated into 4 fractions, each a certain lateral distance from the tumor. In their study they found that all but one case of colorectal cancer were classified as pNo, pN1, pN2 based on the 2 close fraction (at most $3 \mathrm{~cm}$ apart from the tumor) [9] of the 6 cases upstaged to $\mathrm{pN} 1$ it is worth noting that 5 of the cases occurred in the rectum and 3 of those patients had neoadjuvant radiotherapy. Neoadjuvant radiochemotherapy is associated with significantly fewer tumor positive LN [24].

Some study has also shown that radiotheraphy induces significant shrinking of LN within the radiotherapy field $[2,24]$. These finding suggest that LN must be retrieved from all of the fat resected with the rectal cancer surgical specimen to sample an adequate number of total $\mathrm{LN}$ and to detect LN metastases that may be missed by examining mesorectal fat alone. Arguing that LN size does not correlate with the presence of metastases (up to 78\%) of nodes + are smaller than $5 \mathrm{~mm}$ [23] and that very small nodes can easily be missed during examination. Use several fat clearing methods, but those technique are also expansive and time consuming.

We conclude that peritumoral LN are the most susceptible to be metastatic in colon cancer. To decrease the cost effect and the time of colonic cancer surgical specimen management LN should be retrieved only from the pericolic fat close (less than $5 \mathrm{~cm}$ ) to the tumor. If there are less than 4 positive $\mathrm{LN}$ and less than $12 \mathrm{LN}$ examined in total, additional LN should be retrieved from the distal fraction to detect additional metastases. which could result in an upstaged to pN2.

\section{Conclusion}

In our study in $66 \%$ of cases from colonic cancer cases distal fraction dissection was unnecessary, when this recomandation was applied. It is worth noting that the $\mathrm{pN} 2$ stage changes the prognosis. In contrast in the rectal cancer cases specimens systematic sampling of distant LN is mandatary because in rare cases metastases arise in distant LN only, particulary in patients who have had neoadjuvant therapy.

\section{References}

1. Cohen AM, Tremiterra S, Candela F, Thaler HT, Sigurdson ER (1991) Prognosis of node-positive colon cancer. Cancer 67: 1859-1861. [Crossref]

2. Wong JH, Severino R, Honnebier MB, Tom P, Namiki TS (1999) Number of nodes examined and staging accuracy in colorectal carcinoma. J Clin Oncol 17: 2896-2900. [Crossref]

3. Johnson PM, Malatjalian D, Porter GA (2002) Adequacy of nodal harvest in colorectal cancer: a consecutive cohort study. J Gastrointest Surg 6: 883-888. [Crossref]

4. Goldstein NS, Sanford W, Coffey M, Layfield LJ (1996) Lymph node recovery from colorectal resection specimens removed for adenocarcinoma. Trends over time and a recommendation for a minimum number of lymph nodes to be recovered. Am J Clin Pathol 106: 209-216. [Crossref]

5. Goldstein NS (2002) LN recoveries from $2427 \mathrm{pT} 3$ colorectal resection specimens spanning 45 years: recomandations for a minimum number of recovered $\mathrm{LN}$ based on predictive probabilities. Am J Surg Pathol 26: 179-189.

6. Voyer TE, Hanlon AL (2003) Colon cancer survival is associated with increasing number of LN analyzed: a secondary survey of Intergroup Trial INT -0089. J Clin Oncol 15: 2912-2919.

7. Tsai HL (2008) Prognostic significance of depth of invasion, vascular invasion and number of LN retrievals in combination for patients with stage II colorectal cancer undergoing radical resection. $J$ Surg Oncol 97: 384-387.

8. Suzuki O, Sekishita Y, Shiono T, Ono K, Fujimori M, et al. (2006) Number of lymph node metastases is better predictor of prognosis than level of lymph node metastasis in patients with node-positive colon cancer. J Am Coll Surg 202: 732-736. [Crossref]

9. Cserni G, Tarján M, Bori R (2001) Distance of lymph nodes from the tumor: an important feature in colorectal cancer specimens. Arch Pathol Lab Med 125: 246-249. [Crossref] 
10. Greene FL, Page DL (2002) AJCC cancer staging handbook TNM classification of malignant tumors New-York Springer.

11. Sobin LH, Wittekind C (2002) UICC, TNM Classification of malignant tumors NewYork, Wiley Liss.

12. Shirouzu K, Kagegawa T (1995) Distal spread of rectal cancer and optimal distal margin of resection for sphincter preserving surgery cancer 76: 388-392.

13. Wilson SM, Beahrs OH (1976) The curative treatment of carcinoma of the sigmoid, rectosigmoid, and rectum. Ann Surg 183: 556-565. [Crossref]

14. Williams NS, Dixon MF, Johnston D (1983) Reappraisal of the $5 \mathrm{~cm}$ rule of distal excision for carcinoma of the rectum:a study of distal intramural spread and of patients survival. Br J Surg 70: 150-154.

15. Cavessa CF, Bodia F, Fierro S, Fiol V (2018) Anatomic study of the LN of the mesorectum.

16. Thorn CC, Woodcock NP, Scott N, Verbeke C, Scott SB, et al. (2004) What factors affect lymph node yield in surgery for rectal cancer? Colorectal Dis 6: 356-361. [Crossref]

17. Compton CC (2007) Optimal pathologic staging: defining stage II disease. Clin Cancer Res 13: 6862-6870. [Crossref]

18. Miller EA, Woosley J, Martin CF (2004) Hospital to hospital variation in LN detection after colorectal resection cancer 101: 165-171.
19. Vogel C, Kirtil T, Oelling F, Stolte M (2008) LN preparation in resected colorectal carcinoma specimens employing the acetone clearing method. Pathol Res Pract 204 $11-15$.

20. Maurel J, Launoy G, Grosclaude P, Gignoux M, Arveux P, et al. (1998) Lymph node harvest reporting in patients with carcinoma of the large bowel: a French populationbased study. Cancer 82: 1482-1486. [Crossref]

21. Baxter NN, Virnig DJ, Rothenberger DA, Morris AM, Jessurun J, et al. (2005) Lymph node evaluation in colorectal cancer patients: a population-based study. $J$ Natl Cancer Inst 97: 219-225. [Crossref]

22. Martinez Ramos D, Escrig Sas J, Miralles Ten JM (2008) Is there a minimum number of LN that should be examined after surgical resection of colorectal cancer? Cirurgia Espanola 83: 108-117.

23. Kim YM, Sun JH, Cba HJ (2007) Additional LN examination from entire submission of residual mesenteric tissue in colorectal cancer specimens may not add clinical and pathologic relevance. Hum Pathol 38: 762-767.

24. Wichmann MW, Muller C, Meyer G (2002) Effect of preoperative radiochemotherapy on LN retrieval after resection of rectal cancer. Arde Surgery 137: 206-210.

25. Koren R, Siegal A, Klein B, Halpern M, Kyzer S, et al. (1997) Lymph node-revealing solution: simple new method for detecting minute lymph nodes in colon carcinoma. $\mathrm{Dis}$ Colon Rectum 40: 407-410. [Crossref]

Copyright: (C2018 Lorant K. This is an open-access article distributed under the terms of the Creative Commons Attribution License, which permits unrestricted use, distribution, and reproduction in any medium, provided the original author and source are credited. 